\title{
Correction to: First report of edible mushroom Pleurotus ostreatus from India with potential to kill plant parasitic nematodes
}

\author{
R. K. Singh ${ }^{1} \cdot$ Sumit Kumar Pandey ${ }^{1} \cdot$ Dalel Singh $^{1} \cdot$ Prahlad Masurkar $^{1}$
}

Published online: 3 May 2019

(c) Indian Phytopathological Society 2019

\section{Correction to: Indian Phytopathology (2019) 72:173-176 https://doi.org/10.1007/s42360-018-0093-0}

The original version of this article was revised: The article First report of edible mushroom Pleurotus ostreatus from India with potential to kill plant parasitic nematodes, was written by R. K. Singh, Sumit Kumar Pandey, Dalel Singh, and Prahlad Masurkar, was originally published electronically on the publisher's internet portal (currently SpringerLink) on 14 December 2018 with open access.

With the author decision to step back from Open Choice, the copyright of the article changed in April 2019 to (C) Indian Phytopathological Society 2019 and the article is forthwirth distributed under the terms of copyright.

The original article can be found online at https://doi.org/10.1007/ s42360-018-0093-0.

R. K. Singh

rakeshsingh@bhu.ac.in

1 Department of Mycology and Plant Pathology, Institute of Agricultural Sciences, Banaras Hindu University, Varanasi, Uttar Pradesh 221005, India
Publisher's Note Springer Nature remains neutral with regard to jurisdictional claims in published maps and institutional affiliations. 